\title{
First detection of African Swine Fever Virus in Ornithodoros porcinus in Madagascar and new insights into tick distribution and taxonomy
}

\author{
Julie Ravaomanana', Vincent Michaud ${ }^{2}$, Ferran Jori ${ }^{3}$, Abel Andriatsimahavandy ${ }^{4}$, François Roger ${ }^{3}$, \\ Emmanuel Albina², Laurence Vial ${ }^{2^{*}}$
}

\begin{abstract}
Background: African Swine Fever Virus has devastated more than the half of the domestic pig population in Madagascar since its introduction, probably in 1997-1998. One of the hypotheses to explain its persistence on the island is its establishment in local Ornithodoros soft ticks, whose presence has been reported in the past from the north-western coast to the Central Highlands. The aim of the present study was to verify such hypothesis by conducting tick examinations in three distinct zones of pig production in Madagascar where African Swine Fever outbreaks have been regularly reported over the past decade and then to improve our knowledge on the tick distribution and taxonomy.
\end{abstract}

Results: Ornithodoros ticks were only found in one pig farm in the village of Mahitsy, north-west of Antananarivo in the Central Highlands, whereas the tick seemed to be absent from the two other study zones near Ambatondrazaka and Marovoay. Using 16SrDNA PCR amplification and sequencing, it was confirmed that the collected ticks belonged to the $O$. porcinus species and is closely related to the $O$. $p$. domesticus sub-species Walton, 1962. ASFV was detected in 7.14\% (13/182) of the field ticks through the amplification of part of the viral VP72 gene, and their ability to maintain long-term infections was confirmed since all the ticks came from a pig building where no pigs or any other potential vertebrate hosts had been introduced for at least four years.

Conclusions: Considering these results, O. porcinus is a reservoir for ASFV and most likely acts as vector for ASFV in Madagascar, but its apparent restricted distribution may limit its role in the epidemiology of the disease in domestic pigs.

\section{Background}

African Swine Fever (ASF) is one of the most serious diseases in domestic pigs. It is caused by a DNA virus of the Asfarviridae family and usually results in acute haemorrhagic fever in susceptible animals with possibly up to $100 \%$ mortality in naïve pig herds [1]. No treatment or vaccine is currently available, and control is essentially based on preventive sanitary measures and a better knowledge of the epidemiological patterns [1,2]. ASF is enzootic in most sub-Saharan countries and its propagation is considered to be a major risk for other countries.

\footnotetext{
* Correspondence: laurence.vial@cirad.fr

${ }^{2}$ Centre of International Cooperation in Agricultural Research for Development (CIRAD), CMAEE Unit, Campus International de Baillarguet, 34398 Montpellier Cedex 5, France

Full list of author information is available at the end of the article
}

Several introductions have been reported in the past in West Africa, Europe and the Americas, as well as more recent re-emergences of the disease in the Indian Ocean and the Caucasus [2,3].

ASF is highly contagious and is transmitted by direct contact between infected pigs and susceptible ones or by contact with infectious secretions/excretions. The virus is highly resistant in tissues and the environment, contributing to its transmission over long distances through swill feeding and fomites (e.g., contaminated material, vehicles or visitors to pig premises). In addition, African Swine Fever Virus (ASFV) can be transmitted by soft ticks of the genus Ornithodoros, which may either colonise pig pens in domestic areas or mammal burrows in the wild [4-6]. Considering their capacity to replicate and to maintain the virus over the years 
and to transmit the virus "from tick-to-tick" during mating and development stages [7-10], they are also considered excellent reservoirs of ASFV, just like wild African suids (e.g., warthogs, bush pigs and giant forest hogs). Enzootic ASF has been closely linked to the existence of Ornithodoros tick hosts interacting with wild suids, with O. moubata and O. porcinus ticks from the O. moubata species complex in East and Southern Africa [5,11], with O. erraticus in the Iberian Peninsula [6] and perhaps with O. sonrai in Senegal [12].

ASFV was probably introduced into Madagascar in 1997-1998, from the south-eastern coast of Mozambique to the south-western part of the island, with a subsequent and rapid spread to other regions [13,14]. This epizootic disease devastated more than half of the domestic pig population in Madagascar, with severe economic consequences for the local pork meat market [14]. It then evolved into an epi-enzootic pattern, with different hypothetical causes such as the adaptation of ASFV to local resistant pig populations or its establishment and persistence in native bush pigs and local Ornithodoros ticks, supplemented by the lack of reliable sanitary measures to control AFSV epizootic foci. The existence of bush pigs has been confirmed in forested areas of north-western, southern and eastern regions of Madagascar [15], which are considered particularly interesting interface areas for investigating the links between the ASFV sylvatic and domestic cycles. For ticks, specimens from the O. moubata species complex, formerly identified as O. moubata, were known to be present in human houses from north-western coast to Central Highlands of Madagascar and suspected of transmitting human relapsing fever [16-21]. Then, based on morphological descriptions from Walton [22], Uilenberg compared these ticks to some specimens more recently collected in pig pens and concluded that both actually corresponded to the O. porcinus species [23]. Finally, during the epizootic phase in 2000 following ASFV introduction, O. porcinus was collected in pig pens in the Antananarivo region, suggesting a possible close contact between this tick and infected pigs and a potential persistence of ASFV in O. porcinus tick hosts [24]. To date, no more investigations have been conducted, except the preliminary testing of 271 domestic pig sera in 2006 using an ELISA test to detect anti-O. moubata saliva antibodies [25,26]. This test detected $1.1 \%$ of positive sera and $39.1 \%$ of sera were considered doubtful, near Marovoay, Ambatondrazaka and Antananarivo (Ravaomanana and Vial, unpublished data).

The aims of the present work were: (i) to confirm the current presence of $O$. porcinus in pig pens in Madagascar and to better understand its geographical distribution patterns; (ii) to clarify its taxonomy and determine its phylogenetic relationships to known African
Ornithodoros species and subspecies; and (iii) to detect natural long-term infections by ASFV in the Malagasy O. porcinus and to evaluate its potential role in ASFV domestic cycle of transmission in Madagascar.

\section{Methods}

\section{Study zones and periods for field investigations}

Three study zones (Antananarivo, Ambatondrazaka and Marovoay) (Figure 1) were selected and tick examinations in pig pens were conducted during the dry season from July to December in 2006 (Marovoay) and 2007 (Antananarivo and Ambatondrazaka). Only four additional farms were visited in 2008 in the Antananarivo zone to investigate the local distribution of $O$. porcinus. The three zones had large pig populations (from $8 \%$ in the Ambatondrazaka zone to $40 \%$ in the Antananarivo zone of the total Malagasy pig population) and ASF outbreaks had been regularly reported on farms, with an estimated incidence ranging from $15.2 \%$ to $42.5 \%$, depending on the area (Costard, personal communications). Pig production systems varied from traditional small farms in the Marovoay and Ambatondrazaka zones to more industrialised practices for commercial purposes in the Antananarivo zone.

The Marovoay zone consists of a dry and hot tropical coastal zone, characterised by a dry climate throughout the year. The presence of $O$. porcinus (formerly O. moubata) has been reported on the west coast from Mahajunga to Morondava since the $18^{\text {th }}$ century by Drury and confirmed by many authors in the first half of the $20^{\text {th }}$ century [16-21]. However, more recent investigations suggested their quasi extinction since the $1950 \mathrm{~s}$, at least from Soalala to Mahajunga [24,27].

The Ambatondrazaka zone consists of a wet and hot tropical coastal area. The climate is characterised by rainfall throughout the year, especially from December to March. The presence of soft ticks has never been demonstrated in this zone.

The Antananarivo zone consists of highlands characterised by a high-altitude climate, with a hot and wet season from October to February and a dry and cold season from March to September. Although altitude is usually considered unsuitable for the presence of Ornithodoros ticks [28], specimens of O. porcinus were found inside human and animal houses from the $1960 \mathrm{~s}$ to $1980 \mathrm{~s}$ in Mahasolo, $150 \mathrm{~km}$ from Antananarivo $[23,27]$, and in 2000 in Mahitsy, Andralanitra and Tsinjoarivo, north-west of Antananarivo and south of Antananarivo, respectively [24].

\section{Tick collections in pig pens}

In the Marovoay and Ambatondrazaka zones, a random cluster sampling by villages was conducted. The sample size (i.e., the number of farms to be examined in each 

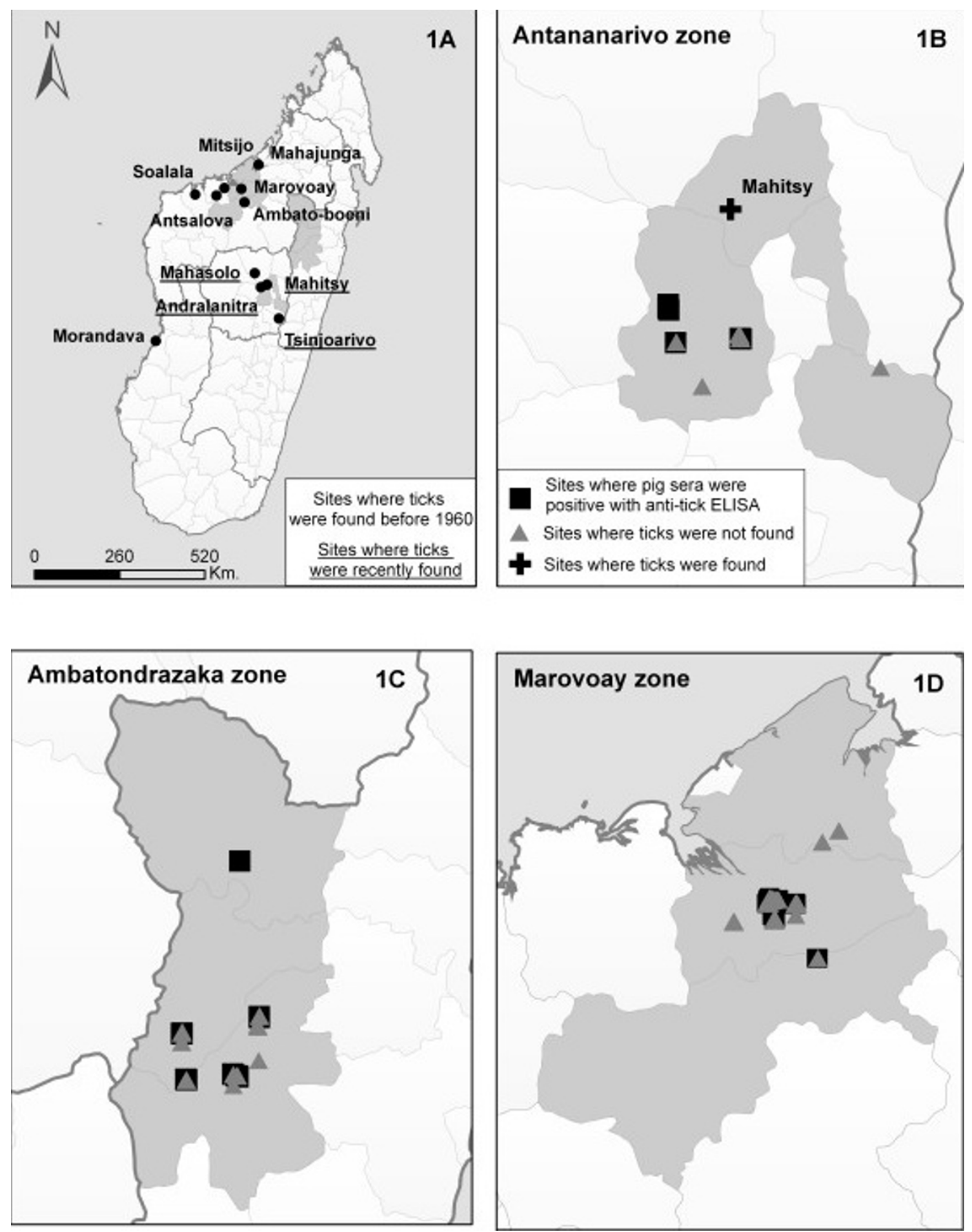

Figure 1 Geographical location of the study zones in Madagascar. (1A) presents the geographical sites where Ornithodoros soft ticks have been previously reported (dark dots with non-underlined names for sites where ticks were found before 1960 and underlined names for those where ticks were recently found). (1B), (1C) and (1D) present specific maps for the Antananarivo, Ambatondrazaka and Marovoay zones, respectively, pinpointing sites where pig sera were positive with the anti-tick ELISA test (dark squares), sites where tick examinations were conducted without finding ticks (grey triangles) and sites where ticks were found (dark crosses). 
village of the study zone) was determined using the "Detection of disease" module of the WINEPISCOPE 2.0. software (free download at http://www.clive.ed.ac. $\mathrm{uk} /$ winepiscope). It was based on the estimated total number of pig farms and the estimated proportion of pig farms to be detected as infested by O. porcinus, with a confidence interval of $95 \%$. The villages examined for tick presence were selected from a preliminary farm census taken in 2006 in the three study zones for domestic pig sampling and were, as much as possible, homogenously distributed within each study zone. An estimated prevalence of infestation of $30 \%$ was used based on previous studies conducted on Ornithodoros ticks colonizing pig farms in Spain and Africa [5,6]. For the Antananarivo zone, we targeted pig farms that were known to be infested in 2000 [24]. Random sampling was then conducted in the Arivonimamo village (Figure 1 ). For the three study zones, one quarter of pig farms that were included in the random sampling were previously detected positive or doubtful using the anti-tick ELISA test in 2006. Finally, if the presence of O. porcinus was confirmed, local investigations were conducted around infested farms in order to determine local tick distribution patterns and the size of tick foci.

Ticks were manually extracted from accessible crevices, small holes and external structures of pig pens, whereas deeper fissures were examined using a portable gasoline-powered vacuum cleaner adapted for burrowdwelling ticks [29]. The content of the collected dust was laid out in a white tray and exposed to the sun in order to collect Ornithodoros soft ticks that are photophobic [30]. Live ticks were placed in small plastic boxes, each of them containing a wet piece of filter paper to maintain a relative humidity suitable for tick survival. In the laboratory, ticks were stored at $-80^{\circ} \mathrm{C}$ until analysis.

\section{Molecular analyses on ticks}

O. porcinus ticks collected during the study, as well as specimens available from previous samplings in 2000, were identified according to morphological features, sex and developmental stage [22,23]. After three washings in $1 \%$ PBS, a tick homogenate was obtained for each specimen by crushing the tick in $1 \mathrm{ml}$ of MEM supplemented with $50 \mathrm{U} / \mathrm{ml}$ of penicillin, streptomycin and fungizone in a 1.5-ml Eppendorf tube. Tick homogenates were frozen twice at $-70^{\circ} \mathrm{C}$ overnight and then vortexed, to facilitate DNA accessibility before storage at $-70^{\circ} \mathrm{C}$.

For molecular use, tick homogenates were centrifuged and DNA extraction was carried out on $200 \mu \mathrm{L}$ of the supernatant using Phenol Chloroform [31]. In order to test the integrity of the extracted DNA, $16 \mathrm{~S} r \mathrm{DNA}$ of each tick was amplified by polymerase chain reaction (PCR) using primers designed specifically for ticks belonging to the $O$. moubata species complex according to the PCR protocol described by Vial [32]. Positive samples were then tested for ASFV infection using a nested PCR that amplified part of the VP72 gene and that was described by Basto [33]. All PCR products were detected by electrophoresis on $1.5 \%$ agarose gel in TAE $1 \mathrm{x}$ buffer (40 mM Tris acetate, 2 mM EDTA, pH 8.3) and stained with ethidium bromide.

\section{Phylogenetic analyses}

To determine phylogenetic relationships of collected ticks and to confirm ASFV infections, some $16 \mathrm{~S} \mathrm{rDNA}$ and VP72 PCR products were directly sequenced using an ABI PRISM 3730xl DNA analyser (Cogenix Meylan, France). Sequences were edited and manually aligned using Seaview software [34]. Phylogenetic trees based on molecular sequences were constructed by applying the neighbor-joining $(\mathrm{NJ})$, the parsimony $(\mathrm{P})$ and the maximum likelihood (ML) algorithms of the Phylip software package, using 1000 bootstraps (BS) with random sequence addition [35]. Single deletion was treated as a fifth base. VP72 amplified sequences were compared to the complete sequence of the gene available for the reference ASFV strain BA71V (M34142 in GenBank). For $16 S$ rDNA alignment, the soft tick Argas persicus from the Argasinae sub-family was used as the outgroup (L34321 in GenBank). Available $16 S$ rDNA sequences of African specimens from the O. moubata species complex were included to refine phylogenetic relationships of Malagasy ticks, especially the reference sequences for O. moubata sensu strict Murray, 1877 (L34328 in GenBank), O. porcinus porcinus Walton, 1962 (L34329 in GenBank) and O. porcinus domesticus Walton, 1962 (L34330 in GenBank) published by Black [36].

\section{Results}

\section{Presence of 0 . porcinus in Malagasy pig pens}

O. porcinus was confirmed in one farm located in Mahitsy (18 $\left.45^{\prime} 3^{\prime \prime} \mathrm{S}, 47^{\circ} 20^{\prime} 47^{\prime \prime} \mathrm{E}\right)$ in the Antananarivo zone (Figure 1 Figure 2). Four other farms were examined in its 20-2000 m periphery without finding any other ticks (Table 1). No tick was found in the nine additional farms that were visited in the Arivonimamo village from the same zone neither among the 70 farms examined in the two other zones (Table 1). In the first zone, it was no more possible to take samples in the Andralanitra and Tsinjoarivo villages because of the recent destruction of the pig premises. In the Marovoay and Ambatondrazaka zones, sampling was incomplete due to ASF foci occurring during the study period and that prevented to finish field investigations for biosafety reasons. As a result, 40 pig pens were visited in the Marovoay zone instead of the 42 expected, with a confidence level ranging from $90 \%$ for Andranofasika to $95 \%$ 


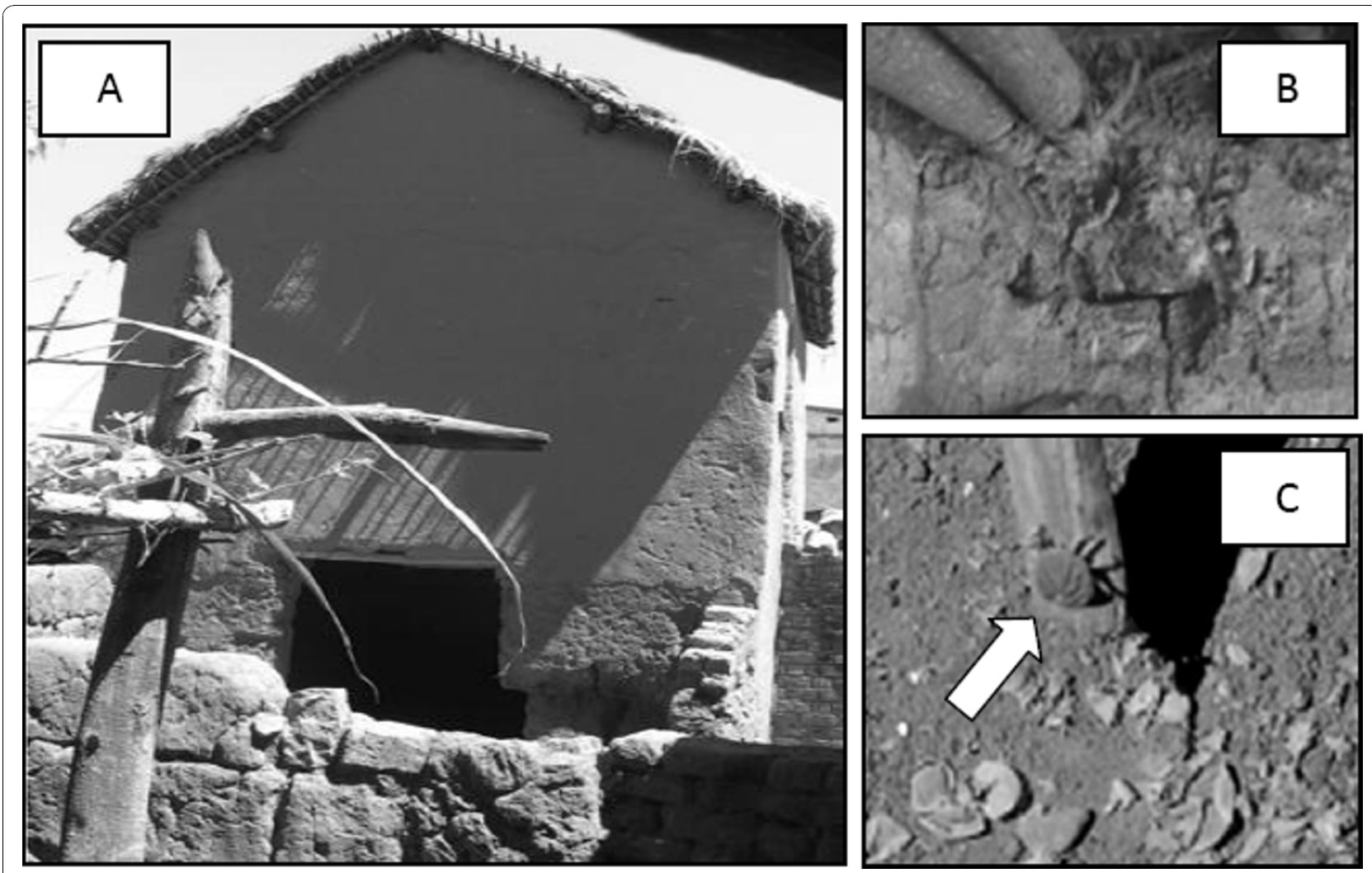

Figure 2 Infested pig farm in Mahitsy (Madagascar). (2A) presents the building where 0 . porcinus ticks have been found. This building is typical from the Antananarivo zone with sand or mud soils, mud or concrete brick walls with few or no apertures except the door, and is located at the ground level of a two-storey human dwelling. (2B) presents one of the cracks inside the building where ticks were found and (2C) shows one tick (pointed by a white arrow) and many sloughed shins collected from these cracks.

Table 1 Sampling protocol and results for tick examinations on pig farms in the three study zones of Madagascar

\begin{tabular}{|c|c|c|c|c|c|c|}
\hline Zone & Village & $\begin{array}{l}\text { Aprox. no. of farms } \\
\text { per village }\end{array}$ & $\begin{array}{c}\text { Sample size for } \\
\text { detection }\end{array}$ & $\begin{array}{l}\text { Visited } \\
\text { farms }\end{array}$ & $\begin{array}{c}\text { Confidence level for } \\
\text { detection (\%) }\end{array}$ & $\begin{array}{l}\text { No. of infested farms } \\
\text { per village }\end{array}$ \\
\hline \multirow[t]{5}{*}{ Marovoay } & $\begin{array}{l}\text { Marovoay/ } \\
\text { Ankazomborona }\end{array}$ & $300-450$ & 9 & 9 & 95 & 0 \\
\hline & Manaratsandry & $100-150$ & 9 & 9 & 95 & 0 \\
\hline & Andranofasika & $25-50$ & 8 & 6 & 90 & 0 \\
\hline & Tsararano & $50-75$ & 8 & 8 & 95 & 0 \\
\hline & $\begin{array}{l}\text { Bekobay/ } \\
\text { Tsilakanina }\end{array}$ & $35-50$ & 8 & 8 & 95 & 0 \\
\hline \multirow{4}{*}{ Ambatondrazaka } & Bejofo & $100-150$ & 9 & 6 & 88 & 0 \\
\hline & Ambatosorotra & $100-150$ & 9 & 8 & 94 & 0 \\
\hline & Ambohimandroso & $50-100$ & 8 & 7 & 92 & 0 \\
\hline & Ambatondrazaka & $200-250$ & 9 & 9 & 95 & 0 \\
\hline \multirow[t]{2}{*}{ Antananarivo } & Arivonimamo & $200-250$ & 9 & 9 & 95 & 0 \\
\hline & Mahitsy & - & - & 5 & - & 1 \\
\hline
\end{tabular}

The table indicates the villages that have been visited, the estimated number of farms to be visited according to the estimated number of existing farms in each village and the real number of farms that have been examined for ticks. Then, the number of infested farms is presented for each village. 
for the other villages. In the Ambatondrazaka zone, 30 pig pens were accessible for tick examination instead of the 35 expected, with a confidence ranging from $92 \%$ to $95 \%$ and decreasing to $88 \%$ for Bejofo.

\section{Molecular identification and phylogeny of Malagasy O. porcinus}

Three $16 S$ rDNA sequences from ticks collected in 2000 in Mahitsy and three from the same location in 2007-2008 were produced. The amplified sequences were identical among ticks from 2000 (HM588698 in GenBank) and 2007-2008 (HM588699 in GenBank), respectively. 273 bps were aligned with available published sequences for phylogenetic analysis. Ninety-four sites were variable and 44 were parsimony informative for the whole dataset (differences at one site represented in at least two different sequences). Within the O. moubata species complex, 50 sites were variables and 22 were parsimony informative. Malagasy ticks from 2000 and 2006-2008 differed by only one substitution. NJ, $\mathrm{P}$ and ML trees had the same configuration. The consensus tree from the ML method is shown on Figure 3. The monophily of the O. moubata species complex and the distinction of $O$. moubata sensu stricto and O. porcinus were supported by $100 \%$ BS values. O. p. porcinus and O. p. domesticus were differentiated with a $89 \%$ BS support. Specimens from South Africa and Zimbabwe that were named $O$. porcinus fell into the O. moubata sensu stricto group with a $60 \%$ BS support. Malagasy ticks were likely related with the reference specimen of O. p. domesticus with a $57 \%$ BS support, and to Tanzanian ticks collected in the $1980 \mathrm{~s}$ and, more recently, in 2003.

\section{Detection of ASFV natural infection in Malagasy 0 . porcinus}

Using PCR amplification of the VP72 virus gene, ASFV infection was detected in 13 ticks out of 182 positive ones for $16 \mathrm{~S}$ rDNA. All stages and sexes were found to be infected. Two out of 21 tested ticks (9.52\% with $95 \%$ CI [8.94-10.09]) were positive in 2000 and 11 out of 161 (6.83\% with 95\% CI [6.34-7.32]) in 2007-2008. The sequencing and the alignment of $243 \mathrm{bps}$ from two amplified fragments (HM588697 in GenBank) confirmed the detection of ASFV since they showed 100\% homology with VP72 amplified from BA71V.

\section{Discussion}

In this present study, O. porcinus was found on a traditional pig farm in Mahitsy in the Antanananarivo zone (Madagascar), confirming previous results related to the presence of $O$. porcinus on the island. The fact that

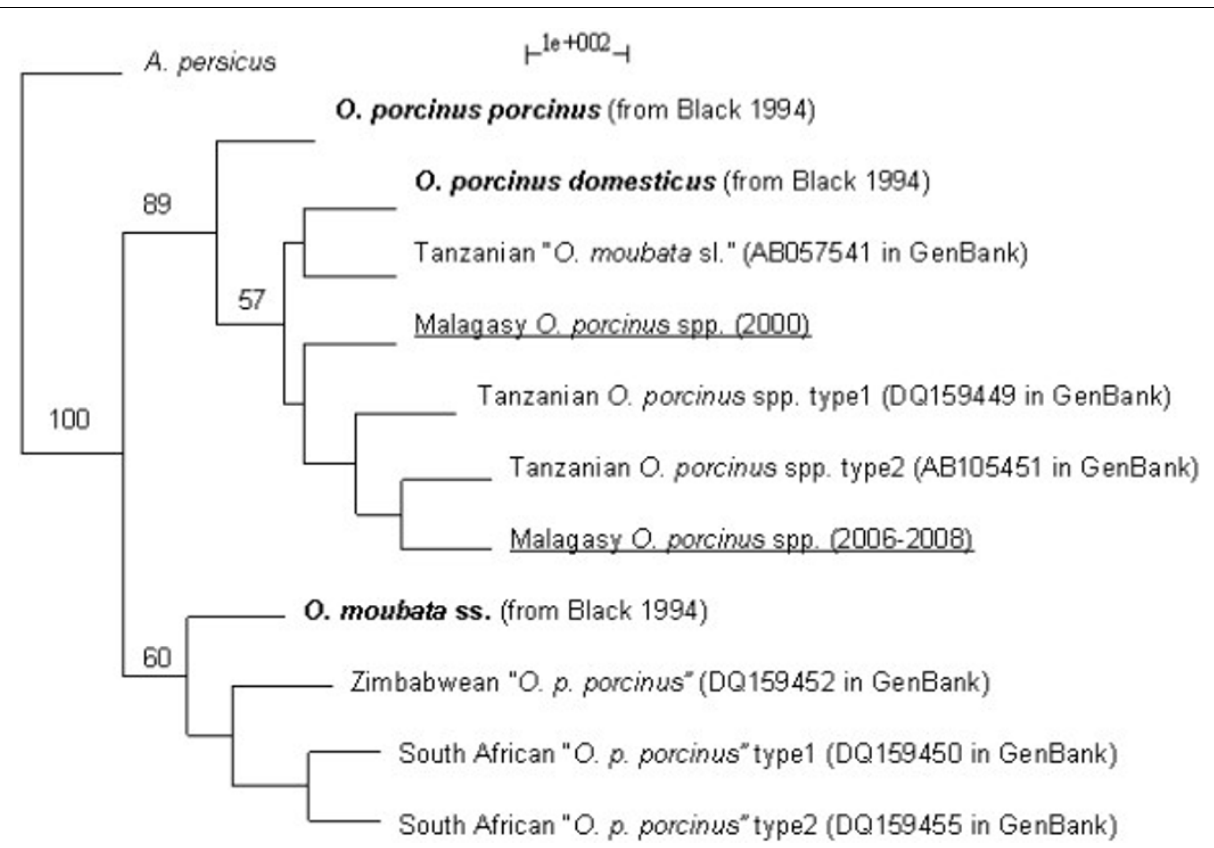

Figure 3 Phylogeny of Malagasy $\boldsymbol{O}$. porcinus spp. ticks. This represents a rooted consensus phylogenetic tree of $16 \mathrm{~S}$ rDNA sequences from Malagasy O. porcinus spp. ticks collected in pig pens in 2000 and 2006-2008 (underlined names), as well as O. moubata sensu stricto, O. p. porcinus and O. p. domesticus reference sequences (bold names) and some other sequences available in GenBank for the O. moubata complex of species, using the Maximum Likelihood (ML) method, with 1000 bootstraps and random sequence addition. Only bootstraps up to $50 \%$ have been indicated and identical sequences have been removed for simplification. Incorrect names given to specimens during field collection are indicated in quotes. 
ticks were found in the same pig pen after an interval of seven years, whereas they were absent from other neighbouring farms, suggests their high propensity to establish stable focal tick populations and their low dispersal capacity. These characteristics have been reported for several Ornithodoros tick species and are linked both to their endophilous lifestyle and their ability to feed rapidly on their hosts (a few minutes to one hour, at least for nymphs and adults) [28,30]. These ticks colonize nests, burrows and caves of vertebrate animals or cracks and crevices in human and livestock habitats. They reduce possible exposure to unfavourable external conditions by rapidly detaching from their vertebrate hosts before these hosts leave the habitat, and by remaining in their underground sheltered habitat. If potential hosts are absent from the habitat, these ticks are also able to survive for several years without feeding, provided the microclimate of their habitat is sufficiently suitable [30].

Our investigations also confirmed that O. porcinus from Madagascar can be infected by ASFV since natural infections with ASFV were detected in about $8 \%$ of tick specimens collected from the Mahitsy farm. Since 2004 until now, the owner of this farm has abandoned pig production since any pigs he has introduced in these pig buildings systematically died from ASFV. Thus the detection of infections in ticks collected in 2000 and then in 2007 from the same pig premises without any introduction of potentially infected pigs (the only confirmed susceptible vertebrate hosts for ASFV with wild suids) for at least three years suggested the capacity of long-term persistence of AFSV in Malagasy O. porcinus. This is in agreement with previous surveys conducted on African Ornithodoros tick vectors concerning virus persistence in the same individuals or among tick populations through transovarial and veneral transmissions $[8,9]$. For the first time, there is field evidence that $O$. porcinus in Madagascar is a natural reservoir for ASFV that most probably also acts as a competent vector. Experimental transmission studies are needed to verify these assumptions.

Furthermore, we were able to clarify the phylogenetic status of $O$. porcinus ticks that colonise pig pens in Madagascar. As previously suggested by Uilenberg [23], these ticks belong to the $O . p$. domesticus sub-species Walton, 1962, although they share some morphological and genetic characteristics of the closely related O. $p$. porcinus Walton, 1962. They are phylogenetically very close to Tanzanian soft ticks that transmit Borrelia duttonii, the agent responsible for human tick-borne relapsing fever in this region [37]. This result suggests that the same $O$. porcinus ticks may be able to maintain and transmit both a human pathogen and an animal pathogen by shifting vertebrate hosts, depending on their availability in their habitat. This is a typical strategy of indiscriminate host feeders to increase the amount of potential hosts and may be interpreted as an adaptation to their endophilous lifestyle [30].

Finally, the distribution range of $O$. porcinus seems to be limited to tiny heterogeneous populations in Madagascar, since ticks were only found in one village of the Central Highlands and seem to be absent from the Morovoay and Ambatondrazaka zones. If such a restricted geographical range is confirmed, the epidemiological role of $O$. porcinus in the persistence of ASFV in Malagasy domestic pigs may be low. These distribution patterns confirm past studies indicating the quasi extinction of this tick since the 1950 s from the northwestern part of the country and the existence of a remaining isolated pocket in the centre of the island today [24,27]. However, they are not consistent with previous serological anti-O. moubata ELISA tests conducted in 2006, which suggested the presence of Ornithodoros ticks in the three study zones. The intrinsic specificity of this test $[26,38]$ and its reliability for the specific Malagasy situation with the $O$. porcinus species have been questioned. Our target sample size was also not met but the maximum risk to not detect an infested farm did not exceed $12 \%$. In addition, our sampling effort might not have revealed tick presence if the real proportion of infested pig pens was lower than the expected prevalence of $30 \%$ established as the threshold in this study. However, this threshold corresponds to the lowest margin that has been observed in endemic African countries and Spain [5,6]. Many interrelated factors may explain the restricted distribution of $O$. porcinus in Madagascar. Cool to hot temperatures from the Marovoay and Ambatondrazaka zones are suitable for the survival and the development of $O$. porcinus but the traditional open buildings typically used for pig rearing in these regions may not provide appropriate habitats for endophilous and photophobic soft ticks $[28,30]$. Conversely, under the harsh and apparently unfavourable climatic conditions of the Central Highlands in the Antananarivo zone, O. porcinus may survive and complete its development cycle in the traditional closed pig buildings encountered in this region, which maintain suitable darkness and humidity for soft ticks and buffer external climatic variations. Locally, the frequency of pig building disinfections using Cresyl (effective acaricide, in addition to its antibacterial, antiviral and antifungal properties), as mentioned by some farmers, may prevent tick establishment. Further investigations on probable recent climate changes in Madagascar and anthropogenic effects such as the increasing use of insecticides for controlling plague or malaria, or the improvement of hygiene in households should also be encouraged in order to identify other factors that might have promoted 
consistent and permanent modifications in the distribution patterns of $O$. porcinus in Madagascar.

\section{Conclusions}

Our examinations of Malagasy pig farms confirmed the presence of a soft tick belonging to the O. porcinus domesticus sub-species Walton, 1962 on the island, at least at one site, and its natural long-term infection by ASFV. The role of this argasid tick in virus maintenance and probably transmission in endemic areas seems to be relevant. However, for unknown reasons, its distribution range in Madagascar seems to have considerably declined over these last decades. Only small scattered infested foci may remain, which might moderate the role of this soft tick in the observed persistence of ASFV in Malagasy domestic pigs since its introduction more than ten years ago.

\begin{abstract}
Acknowledgements
I would like to thank the following people: Solenne Costard (Royal Veterinary College, London) for her assistance in defining sampling protocols and organising field investigations on pigs in Madagascar; Céline Humbert, Stéphanie Franco and Harentsoaniaina Rasamoelina Andriamanivo (MsC students at the CIRAD, Montpellier) for collecting pig sera in Madagascar; Adrien Bretaudeau (MsC student at the CIRAD, Montpellier) for collecting data on facilities and pig treatments in the village of Arivonimamo in Madagascar; Frédéric Stachurski (CIRAD, Antananarivo) for collecting ticks in the field; Camille Danes (CIRAD, Montpellier) for editing the maps of Madagascar and specific study zones; Dr Ricardo Perez-Sanchez (University of Salamanca, Spain) for testing pig sera using the anti-O. moubata ELISA test, as a preliminary approach, and Gail Wagman for editing the English manuscript. This work was supported by the Wellcome Trust (№210183. 183, AHDW/03/04) (http://www.wellcome.ac.uk/index.htm).
\end{abstract}

\section{Author details}

${ }^{1}$ National Centre of Applicable Research for Rural Development (FOFIFA/ DRZV), BP 4, Antananarivo, Madagascar. ${ }^{2}$ Centre of International Cooperation in Agricultural Research for Development (CIRAD), CMAEE Unit, Campus International de Baillarguet, 34398 Montpellier Cedex 5, France. ${ }^{3}$ CIRAD, AGIRs Unit, Campus International de Baillarguet, 34398 Montpellier Cedex 5, France. ${ }^{4}$ Science Faculty, Antananarivo University, BP 566, Antananarivo, Madagascar.

\section{Authors' contributions}

JR performed field tick collections and laboratory analyses on tick and pig samples. She wrote part of the methods. VM and EA supervised laboratory analyses. FJ, AA and FR assisted with field investigations and data analyses. LV designed the sampling protocol, supervised field investigations, analysed data and wrote the remaining sections of the paper. All authors read and approved the final manuscript.

\section{Competing interests}

The authors declare that they have no competing interests.

Received: 21 July 2010 Accepted: 30 November 2010

Published: 30 November 2010

\section{References}

1. Arias M, Sanchez-Vizcaino JM: African Swine Fever. In Trends in emerging viral infections of swine. Edited by: Morilla A, Yoon KJ, Zimmerman JJ. Ames: lowa State University Press; 2000:119-124.

2. Costard S, Wieland B, de Glanville William, Jori F, Rowlands R, Voslo W, Roger F, Pfeiffer DU, Dixon LK: African swine fever: how can global spread be prevented? Philos Trans R Soc Lond B Biol Sci 2009, 364:2683-2696.
3. Rowlands RJ, Michaud V, Heath L, Hutchings G, Oura C, Vosloo W, Dwarka R, Onashvili T, Albina E, Dixon LK: African swine fever virus isolate, Georgia, 2007. Emerg Infect Dis 2008, 14:1870-1874.

4. Plowright W, Parker J, Pierce MA: African Swine Fever Virus in ticks (Ornithodoros moubata, Murray) collected from animal burrows in Tanzania. Nature 1969, 221:1071-1073.

5. Haresnape JM, Wilkinson PJ: A study of African swine fever virus infected ticks (Ornithodoros moubata) collected from three villages in the ASF enzootic area of Malawi following an outbreak of the disease in domestic pigs. Epidemiol Infect 1989, 102:507-522.

6. Oleaga-Pérez A, Pérez-Sanchez R, Encinas-Grandes A: Distribution and biology of Ornithodoros erraticus in parts of Spain affected by African swine fever. Vet Rec 1990, 13:32-37.

7. Plowright $W$, Perry $C T$, Pierce MA, Parker J: Experimental infection of the argasid tick, Ornithodoros moubata porcinus, with African swine fever virus. Arch Gesamte Virusforsch 1970, 31:33-50.

8. Plowright $W$, Perry $C T$, Pierce MA: Transovarial infection with African swine fever virus in the argasid tick, Ornithodoros moubata porcinus, Walton. Res Vet Sci 1970, 11:582-584.

9. Plowright W, Perry $C T$, Greig A: Sexual transmission of African swine fever virus in the tick, Ornithodoros moubata porcinus, Walton. Res Vet Sci 1974, 17:106-113.

10. Basto AP, Nix RJ, Boinas F, Mendes S, Silva MJ, Cartaxeiro C, Portugal RS, Leitão A, Dixon LK, Martins C: Kinetics of African swine fever virus infection in Ornithodoros erraticus ticks. J Gen Virol 2006, 87:1863-1871.

11. Walton GA: The Ornithodoros moubata subspecies problem in relation to human relapsing fever epidemiology. Symp Zool Soc Lond 1962, 6:83-156.

12. Vial L, Wieland B, Jori F, Etter E, Dixon L, Roger F: African Swine Fever virus DNA in soft ticks, Senegal. Emergg Infect Dis 2007, 13:1928-1931.

13. Gonzague M, Roger F, Bastos A, Burger C, Randriamparany T, Smondack S, Cruciere C: Isolation of a non-haemadsorbing, non-cytopathic strain of African swine fever virus in Madagascar. Epidemiol Infect 2001, 126:453-459.

14. Rousset $\mathrm{D}$, Randriamparany $\mathrm{T}$, Maharavo Rahantamalala $\mathrm{CY}$, Randriamahefa N, Zeller H, Rakoto-Andrianarivelo M, Roger F: Introduction de la peste porcine africaine à Madagascar, histoire et leçons d'une émergence. Arch Inst Pasteur Madagascar 2001, 67:31-33.

15. Andrianjakarivelo V: Artiodactyla Potamochoerus larvatus, Bush Pig, Lambo, Lambodia, Lamboala, Antsanga. In The Natural History of Madagascar. Edited by: Goodman S, Benstead J. Chicago: The University of Chicago Press; 2003:1365-1367.

16. Lamoureux A: Présence d'Ornithodorus moubata dans un foyer de fièvre récurrente à la côte ouest de Madagascar. Bull Soc Path Exot 1913, 6:146-149.

17. Suldey EW: La fièvre récurrente malgache. Origine. Mode de propagation. Extension. Bull Soc Path Exot 1916, 9:688-693.

18. Poisson H: Les maladies parasitaires à Madagascar. Rev Sci Illust 1931, 69:230-237.

19. Le Gall R: Vue d'ensemble sur les maladies pestilentielles, endémoépidémiques, transmissibles et sociales a Madagascar entre 1936 et 1940. Bull Off Int Hyg Publ 1943, 35:417-450.

20. Néel R, Payet $M$, Gonnet C: La fièvre récurrente à tiques de Madagascar. Historique, Etat actuel de la question. Bull Soc Path Exot 1949, 42:384-394.

21. Colas-Belcour J, Néel R: Contribution à l'étude de la transmission du spirochete de la fièvre récurrente malgache (Borrelia duttonii) par des Ornithodorus moubata de même origine. Bull Soc Path Exot 1952, 45:69-78.

22. Walton GA: The Ornithodoros moubata subspecies problem in relation to human relapsing fever epidemiology. Symp Zool Soc Lond 1962, 6:83-156.

23. Uilenberg G: Existence de Ornithodorus porcinus Walton, 1962 (Argasidae) à Madagascar. Rev Elev Méd Vét Pays Trop 1963, 16:147-150.

24. Roger F, Ratovonjato J, Vola P, Uilenberg G: Ornithodoros porcinus ticks, bushpigs, and African swine fever in Madagascar. Exp Appl Acarol 2001, 25:263-269.

25. Canals A, Oleaga A, Pérez R, Domingez J, Encinas A, Sánchez-Vizcaino JM: Evaluation of an enzyme-linked immunosorbent assay to detect specific antibodies in pigs infested with the tick Ornithodoros erraticus (Argasidae). Vet Parasitol 1990, 37:145-153.

26. Baranda JA, Pérez-Sanchez R, Oleaga-Pérez A, Encinas-Grandes A: Antigens of interest for the diagnosis of parasitism in pigs by Ornithodoros erraticus and Ornithodoros moubata. J Parasitol 1997, 83:831-838. 
27. Rodhain $F$, Fontenille $D$ : La récurrente à tiques malgache, une affection éradiquée? Bull Soc Path Exot 1989, 82:192-198.

28. Morel PC: Les tiques d'Afrique et du Bassin Méditerranéen [CDROM]. Montpellier: CIRAD Editions; 2003.

29. Butler JF, Holscher KH, Adeyeye O, Gibbs EPJ: Sampling techniques for burrow dwelling ticks in reference to potential African swine fever virus vectors. In Acarology VI. Volume 2. Edited by: Griffiths DA, Bowman CE. Chichester: Ellis Horwood; 1984:1065-1074.

30. Vial L: Biological and ecological characteristics of soft ticks (Ixodida: Argasidae) and their impact for predicting tick and associated disease distribution. Parasite 2009, 16:191-202.

31. Halos L, Jamal T, Vial L, Maillard R, Suau A, Le Menach A, Boulouis HJ, Vayssier-Taussat M: Determination of an efficient and reliable method for DNA extraction from ticks. Vet Res 2004, 5:1-18.

32. Vial L, Durand P, Arnathau C, Halos L, Diatta G, Trape JF, Renaud F: Molecular divergences of the Ornithodoros sonrai soft tick species, a vector of human relapsing fever in West Africa. Microbes Infect 2006, 8:2605-2611.

33. Basto AP, Portugal RS, Nix RJ, Cartaxeiro C, Boinas F, Dixon LK, Leitão A, Martins C: Development of a nested PCR and its internal control for the detection of African swine fever virus (ASFV) Ornithodoros erraticus. Arch Virol 2006, 151:819-826.

34. Galtier N, Gouy M, Gautier C: SEAVIEW and PHYLO_WIN: two graphic tools for sequence alignment and molecular phylogeny. Comput Appl Biosci 1996, 12:543-548.

35. Felsenstein J: Confidence limits on phylogenies: an approach using the bootstrap. Evolution 1985, 39:783-791.

36. Black WC, Piesman J: Phylogeny of hard-and soft-tick taxa (Acari: Ixodida) based on mitochondrial $16 \mathrm{~S}$ rDNA sequences. Evolution 1994, 91:10034-10038.

37. Fukunaga $M$, Ushijima $Y$, Aoki $Y$, Talbert A: Detection of Borrelia duttonii, a tick-borne relapsing fever agent in Central Tanzania, within ticks by Flagellin gene-based nested polymerase chain reaction. Vector Borne Zoonotic Dis 2001, 1:331-338.

38. Oleaga-Pérez A, Pérez-Sanchez R, Astigarraga A, Encinas-Grandes A: Detection of pig farms with Ornithodoros erraticus by serology. Elimination of non-specifc reactions by carbohydrate epitopes of salivary antigens. Vet Parasitol 1994, 52:97-111.

doi:10.1186/1756-3305-3-115

Cite this article as: Ravaomanana et al:: First detection of African Swine Fever Virus in Ornithodoros porcinus in Madagascar and new insights into tick distribution and taxonomy. Parasites \& Vectors 2010 3:115.

\section{Submit your next manuscript to BioMed Central and take full advantage of:}

- Convenient online submission

- Thorough peer review

- No space constraints or color figure charges

- Immediate publication on acceptance

- Inclusion in PubMed, CAS, Scopus and Google Scholar

- Research which is freely available for redistribution

Submit your manuscript at www.biomedcentral.com/submit
Biomed Central 